\title{
Effect analysis of grouting reinforcement ring considering fluid solid coupling
}

\author{
Heng Zhou ${ }^{1, *}$, Xiaochen Wang ${ }^{1}$, Haojie Liu ${ }^{1}$,Yanan $\mathrm{Liu}^{1}$, Chenyang $\mathrm{Ma}^{1}$, and Kexian $\mathrm{Li}^{2}$ \\ ${ }^{1}$ College of civil engineering and water conservancy of Shandong University, Jinan, China, 250061 \\ ${ }^{2}$ Qingdao metro line one line limited company, Qingdao, Shandong, 266000, China
}

\begin{abstract}
Geological hazards such as instability of surrounding rock and leakage of water are easily occurred in subway tunnels crossing water rich sand layers. Based on the principle of fluid solid coupling in porous media, this paper studies the plastic zone distribution of surrounding rock and reinforcement ring, vertical settlement of tunnel vault and water seepage of tunnel before and after grouting reinforcement for water rich sand layer. Considering the compressibility of rock mass, the relationship between porosity, permeability and volume strain is further deduced and simplified. A set of numerical calculation formula is set up to study the change of physical parameters of the water rich sand layer before and after grouting to determine the grouting effect and select the thickness of the best grouting reinforcement ring. The results show that the deformation and water permeability of the tunnel decrease with the increase of the thickness of the grouting reinforcement ring. The thickness of the grouting reinforcement ring is the most reasonable when the thickness of the reinforcing ring reaches a certain value, and the thickness of the grouting reinforcement ring is designed to be $5 \sim 6 \mathrm{~m}$. The research results have been successfully applied in the grouting project of Qingdao Metro stone elderly bathing beach. The reliability of the numerical simulation is verified by comparing the data from the field monitoring and measurement, providing reference for the related projects.
\end{abstract}

\section{Introduction}

With the rapid development of construction, municipal, water conservancy and transportation projects, more and more projects need to be constructed in extremely complex strata, which leads to a large number of underground disaster prevention and control problems, and grouting[1-3] reinforcement is a traditional method of underground engineering disaster prevention and control. The full-section curtain grouting is often used to reinforce the water-rich strata in subway tunnels. However, due to the different rock formations in different areas, the properties of the rock and soil are complicated and changeable, so it is difficult to put forward a practical grouting design scheme.

About the mechanism of grouting reinforcement ring and the stability of surrounding rock. Wang Gang[4] optimized the parameters selection of grouting reinforcement ring for typical water rich stratum tunnels. Chen Jiankuang[5] analyzed the process of pore water

\footnotetext{
*Corresponding author: 1192582720@qq.com
} 
pressure dissipation in grouting reinforcement ring. Study on fluid structure interaction in tunnel excavation. Li Lu et al.[6] established a fluid solid coupling model describing the diffusion of viscous slurry in porous media.Ye Yuanxin et al.[7] systematically summarized and introduced the coupling characteristics of rock seepage. The numerical simulation of fluid structure interaction is considered. Ju Minghui[8] studied the pore fluid flow due to tectonic deformation by numerical simulation. Li Shuchen et al.[9] established a quantitative index to evaluate the stability of surrounding rock by solving the safety factor of surrounding rock stability. A large number of scholars have studied the effect of grouting reinforcement ring. But they often simplify the tunnel into a circular section and consider the influence of the lining system on the surrounding rock. In fact, tunnels are generally designed to be eggshell or horseshoe shaped. When curtain grouting is used to control bad strata, the reinforcement ring should ensure excavation safety before the lining is formed. It is more practical to consider only the effect of grouting reinforcement ring on surrounding rock. Furthermore, the coupling effect of stress field, displacement field and seepage field should be considered in the study of grouting reinforcement circle.

This paper takes the underground horizontal channel grouting project of Qingdao stone old bathing station as an example. The relationship among porosity, permeability and volumetric strain is further simplified by using the Kozeni-Kalman equation, and a set of numerical formulas for fluid-solid coupling is established. With the help of numerical simulation software, the variation characteristics and interaction of stress field, displacement field and seepage field of surrounding rock before and after grouting are studied, and the influence of thickness and permeability of reinforcement ring on stability of surrounding rock and water inflow of tunnel is further studied. The grouting effect is discussed and the parameter design of reinforcement ring is optimized to provide reference for other similar projects.

\section{Engineering survey}

\subsection{An overview of the station}

Qingdao Metro stone elderly bathing station is a station on Qingdao Metro Line 2. The station crossing water rich sand layer. The grade of strata is grade VI, water content is high, and self stability ability is very poor. Influenced by the Wanggezhuang fault, mylonite, sandy clastic rock and massive clastic rock are developed in the tectonic fracture zone. Site grouting construction is as shown in figure 1.

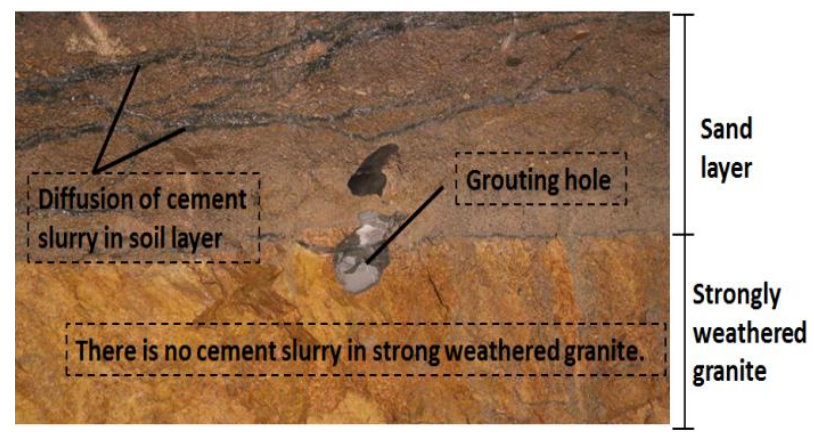

Fig. 1. Site grouting construction drawing.

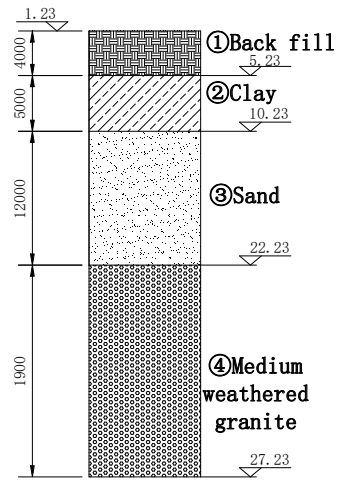

Fig. 2. Soil layer distribution map. 
Table 1. layer parameter table.

\begin{tabular}{|c|c|c|c|c|c|}
\hline $\begin{array}{c}\text { Type of } \\
\text { surrounding rock }\end{array}$ & $\begin{array}{c}\text { bulk modulus } \\
K(\mathrm{MPa})\end{array}$ & $\begin{array}{c}\text { shear } \\
\text { modulus } \\
G(\mathrm{MPa})\end{array}$ & $\begin{array}{c}\text { angle of } \\
\text { friction } \\
\varphi\left(^{\circ}\right)\end{array}$ & $\begin{array}{c}\text { cohesive } \\
\text { strength } \\
C(\mathrm{MPa})\end{array}$ & $\begin{array}{c}\text { unit weight } \\
\gamma\left(\mathrm{kN} \cdot \mathrm{m}^{-3}\right)\end{array}$ \\
\hline Back fill & 6 & 2.22 & 9 & 0.2 & 18.5 \\
\hline Clay & 12 & 4.62 & 18 & 0.275 & 19.7 \\
\hline Sand & 25 & 9.68 & 3.00 & 0.1 & 25 \\
\hline $\begin{array}{c}\text { Medium weathered } \\
\text { granite }\end{array}$ & 50 & 22 & 45 & 12 & 41 \\
\hline
\end{tabular}

\subsection{Parameters of surrounding rock}

According to the geological investigation report of stone elderly bathing station of Qingdao Metro Line 2 and the Engineering Geology Manual, the distribution of underground rock and soil in the study section is shown in figure 2. The physical and mechanical parameters of the engineering section obtained from the relevant documents are shown in table 1 . The ultimate aim of the grouting reinforcement in this project is to form a grouting stone in the direction of $40 \mathrm{~m}$ in the direction of the excavation face along the direction of the tunnel, so as to prevent the instability of the surrounding rock excavation caused by the tunnel crossing the water rich sand layer.

\section{Model establishment}

The underground passageway of Qingdao stone elderly bathing station is the engineering background of numerical simulation. The coupling effect between stress field, displacement field and seepage field of surrounding rock during grouting treatment is considered when the corresponding finite element analysis model is established. The coupling system consisting of water rich sand layer, grouting reinforcement area and surrounding rock is simulated.

\subsection{Constitutive equation}

Fluid solid interaction has a significant effect on the grouting reinforcement process in the water rich formation. In order to simplify the problem, the surrounding rock can be regarded as homogeneous, isotropic elastic porous media. The governing equations of fluid solid coupling are as follows.

(1) the motion equation of groundwater seepage.

The groundwater seepage in the water rich stratum belongs to the passive non steady state problem. Its continuity equation is:

$$
\frac{\partial(\rho \phi)}{\partial t}+\nabla \cdot(\rho V)=0
$$

Considering the fluid solid coupling[10-11], the equation of state of surrounding rock:

$$
\rho_{s}=\rho_{s 0}\left[1+\frac{p-p_{0}}{E}-\frac{\sigma^{\prime}-\sigma_{0}^{\prime}}{(1-\phi) E}\right]
$$

where $p$ is ground water pressure $(P a)$, and $p_{0}$ is initial groundwater pressure $(P a)$. E is modulus of elasticity $(P a) . \phi$ is porosity of rock and soil. $\rho_{s}$ is density of surrounding 
$\operatorname{rock}\left(\mathrm{kg} / \mathrm{m}^{3}\right)$, and $\rho_{s 0}$ is initial density of surrounding $\operatorname{rock}\left(\mathrm{kg} / \mathrm{m}^{3}\right) \cdot \sigma^{\prime}$ is effective stress of surrounding rock, and $\sigma_{0}^{\prime}$ is effective stress of initial surrounding rock.

(2)The control equation of the stress field of rock and soil [12].

Considering the effect of hydrostatic pressure $p$ on the basis of elastic relation, the constitutive equation is written as follows:

$$
\begin{gathered}
\varepsilon_{i j}=\frac{1+v}{E} \sigma_{i j}-\frac{v}{E} \sigma_{k k} \delta_{i j}+\frac{\alpha}{3 K^{\prime}}\left(p-p_{0}\right) \delta_{i j} \\
\varepsilon_{k k}=\frac{1-2 v}{E} \sigma_{k k}+\frac{\alpha}{3 K^{\prime}}\left(p-p_{0}\right) \delta_{i j}
\end{gathered}
$$

where $\sigma_{i j}, \sigma_{k k}$ is stress of rock and soil mass $(P a) . v$ is poisson ratio. $\varepsilon_{i j}, \varepsilon_{k k}$ is strain of surrounding rock. $\alpha$ is Biot modulus. $K^{\prime}$ is volume modulus of surrounding rock. $\delta_{i j}$ is kronecker symbols in tensor form.

(3)Permeability[13-14] of surrounding rock.

Considering the fluid solid coupling, the relationship between porosity and volumetric strain can be expressed as:

$$
\phi=\frac{\phi_{0}+\varepsilon_{v}+\left(1-\phi_{0}\right) \Delta p / K_{s}}{1+\varepsilon_{v}}
$$

where $\varepsilon_{v}$ is volumetric strain of surrounding rock, and $\varepsilon_{v}=\frac{\partial u}{\partial x}+\frac{\partial v}{\partial y}+\frac{\partial w}{\partial z} . \phi_{0}$ is initial porosity. $\Delta p$ is variation of hydrostatic pressure $(P a) . K_{s}$ is model parameter.

According to the Calman equation[15],the volume change of surrounding rock is simplified as the pore volume change of surrounding rock. After further simplification, the permeability of surrounding rock satisfies the equation:

$$
K=K_{0} \frac{1}{1+\varepsilon_{v}}\left(1+\frac{\varepsilon_{v}}{\phi_{0}}\right)^{3}
$$

where $K_{0}$ is initial permeability.

\subsection{Constitutive equation}

The stone elderly bathing station of Qingdao Metro passes through the water-rich sand layer, and the risk of grouting reinforcement is very great. Therefore, it is necessary to evaluate the stability of surrounding rock of this stratum. In this paper, the finite element[15] software COMSOL Multiphysics is used to simulate the coupling between porous media and solid mechanics. Combined with the possible instability of surrounding rock and groundwater seepage inflow, the numerical analysis and calculation with strong pertinence are carried out.

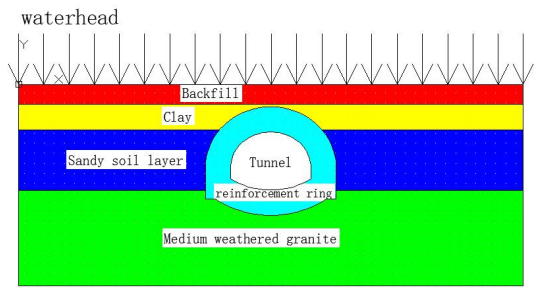

Fig. 3. Numerical simulation model.

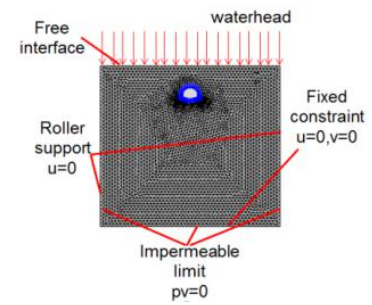

Fig. 4. Model boundary condition. 
The numerical model is composed of surrounding rock and grouting reinforcement circle. The rock and soil are saturated with water. The research problem is steady state. The calculation model is shown in figure 3. The study is simplified to plane strain problem, and two dimensional finite element model is established as shown in figure 4.

Referring to the data of related projects, the physical and mechanical parameters of the reinforcing ring are determined by sampling experiment of the reinforcing ring after grouting in water-rich sand layer, as shown in table 2.

Table 2. Calculation parameters of numerical model.

\begin{tabular}{|c|c|c|c|c|c|c|c|}
\hline $\begin{array}{c}\text { Material } \\
\text { name }\end{array}$ & $\begin{array}{c}\text { Density } \\
\left(10^{3} \mathrm{~kg} / \mathrm{m}^{3}\right)\end{array}$ & $\begin{array}{c}\text { Modulus of } \\
\text { elasticity } \\
(\mathrm{MPa})\end{array}$ & $\begin{array}{c}\text { Poisson } \\
\text { ratio }\end{array}$ & $\begin{array}{c}\text { internal } \\
\text { friction } \\
\text { angle } \\
()^{\circ}\end{array}$ & $\begin{array}{c}\text { Cohesive } \\
\text { force } \\
(\mathrm{MPa})\end{array}$ & $\begin{array}{c}\text { Permeability } \\
\left(\mathrm{m}^{2}\right)\end{array}$ & porosity \\
\hline $\begin{array}{c}\text { Grouting } \\
\text { reinforce } \\
\text { ment ring }\end{array}$ & 3.00 & 2000 & 0.32 & 25 & 2.15 & $5 \times 10^{-12}$ & 0.01 \\
\hline
\end{tabular}

\section{Result analysis}

In this simulation, the mechanical parameters of water-rich sand layer before and after grouting are brought into the numerical simulation to calculate. The effect of grouting reinforcement ring is analyzed, and the risk of tunnel excavation is determined.

\subsection{Analysis of effect of grouting reinforcement ring}

The settlement of vault caused by tunnel excavation before and after grouting is shown in figure 5 and figure 6 . The figure shows that the closer the settlement is to the part of the tunnel, the more obvious the effect is. The maximum settlement is at the center of the tunnel, which is 100 meters away from the initial section. Comparing with figure 5 and figure 6 , the settlement of tunnel vault decreased from $0.24 \mathrm{M}$ to $0.019 \mathrm{~m}$ after grouting reinforcement circle was formed. It can be seen that the grouting reinforcement forms a compact stone around the tunnel, enhances the elastic modulus, porosity and other physical and mechanical parameters of the water-rich sand layer, and the grouting reinforcement ring has obvious effect on limiting the tunnel vault settlement.

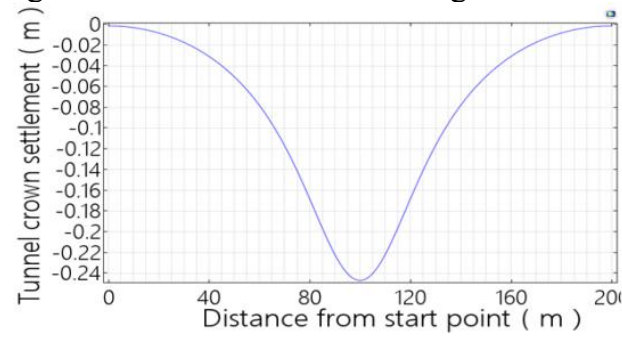

Fig.5. Settlement of tunnel vault before grouting reinforcement.

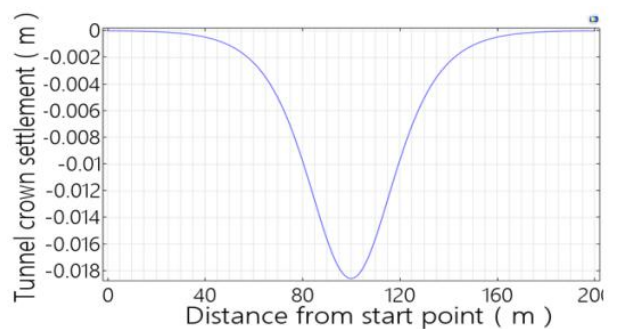

Fig. 6. Settlement of tunnel vault after grouting reinforcement.

The plastic deformation around the tunnel before and after grouting is shown in figure 7 and figure 8 . From the figure 7, it can be seen that a large number of plastic zones appear at the arch foot and waist of the tunnel before the grouting reinforcement circle is formed, and the plastic zones almost run through the left and right. At this time, the rock and soil mass basically loses the ability to bear the stress and deformation. According to figure 8 , after forming the grouting reinforcement ring, the plastic zone is formed only in the minimum area of the arch foot of the tunnel. There is no tendency to pass through the reinforcing ring, 
which ensures that the reinforcing ring will not be unstable due to plastic deformation. The cohesion and internal friction angle of grouting reinforcement ring are greatly increased compared with before reinforcement, which greatly limits the plastic deformation and failure of surrounding rock. The effect of grouting reinforcement ring on the plastic deformation of surrounding rock in tunnel excavation is obvious.

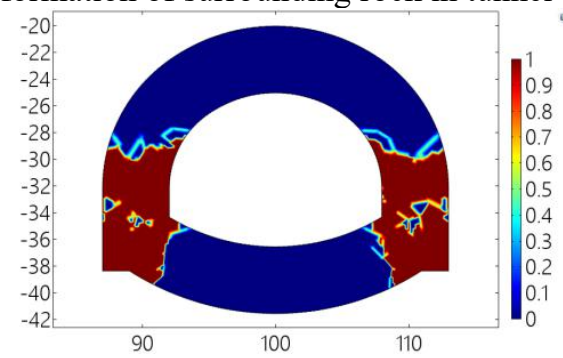

Fig. 7. Plastic deformation around the surrounding tunnel.

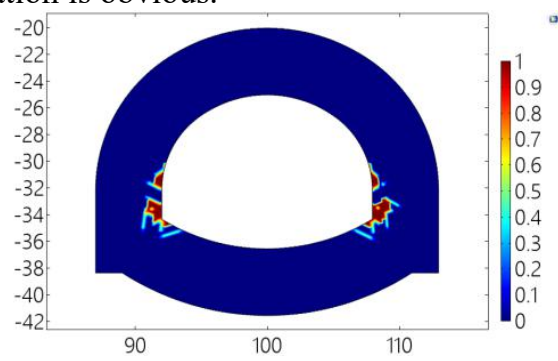

Fig. 8. Plastic deformation of reinforced ring after reinforcement.

The seepage velocity before and after grouting is shown in figure 9 and figure 10 . After the tunnel is excavated, the groundwater flows into the tunnel under the action of Darcy's law. Excessive infiltration of tunnel will form a permeable channel around the tunnel and destroy the stability of surrounding rock. As shown in figure 9, the arrow indicates the size of the water head. The soil around the tunnel is a water-rich sand layer with strong permeability and high porosity. Due to the gap formed by the tunnel excavation, the groundwater flows from the outside of the tunnel to the interior. The seepage effect of groundwater is obvious, which is extremely unfavorable to tunnel excavation. From figure 10 , we can see that after the formation of the grouting reinforcement ring, the seepage velocity of the ground water decreases. This is because the physical and mechanical parameters of the water-rich sand layer around the tunnel are improved, and the permeability coefficient and porosity are greatly reduced. The formation of grouting reinforcement ring has obvious effect on controlling the leakage of water in the tunnel.

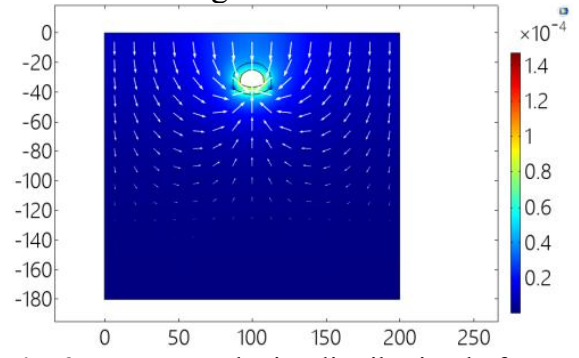

Fig. 9. Seepage velocity distribution before reinforcement.

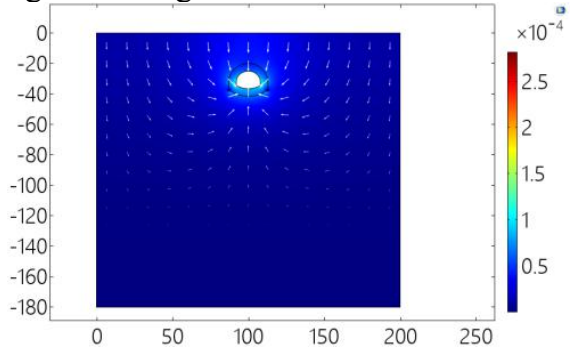

Fig.10. The velocity of seepage flow after reinforcement.

\subsection{Optimization of parameters of grouting reinforcement ring}

From the above analysis, we can see that the grouting reinforcement ring has the function of improving the water rich sand layer. It can be seen that grouting reinforcement plays an obvious role in the tunnel crossing the poor water bearing stratum. However, the above analysis only takes into account the condition that the thickness of the grouting reinforcement is $5 \mathrm{~m}$. Obviously, in the case of the same grouting material and the same grouting method, the thickness of the grouting reinforcement ring plays a decisive role in the effect of the grouting reinforcement.

The above analysis shows that the settlement of tunnel vault and the horizontal displacement of tunnel are mainly determined by the elastic modulus of grouting 
reinforcement ring, and the amount of water gushing is mainly controlled by the permeability coefficient of grouting reinforcement ring. Therefore, when the parameters of grouting reinforcement ring are optimized, the variation of tunnel deformation and seepage with the thickness of grouting reinforcement ring under different elastic modulus and different permeability coefficient are considered respectively.

\subsubsection{When the elastic modulus of reinforcement ring is different, the settlement and offset values of the tunnel vary with the thickness of the reinforcing ring}

The thickness of the reinforcing ring is set by 16 parameters from $1 \sim 16 \mathrm{~m}$. $\mathrm{M}$ is taken as the ratio of elastic modulus( $E_{g}$ )and surrounding rock elastic modulus( $E_{s}$ )of grouting reinforcement ring. The elastic modulus $E_{s}=100 \mathrm{Mpa}$ and $\mathrm{m}$ of the surrounding rock take 6 different values, as shown in table 3 .

Table 3. Elastic modulus value table of

\begin{tabular}{|c|r|c|}
\hline $\begin{array}{c}\text { Thickness of } \\
\text { reinforcement } \\
\text { ring(m) }\end{array}$ & $\begin{array}{c}\text { reinforcement } \\
\mathrm{m}=\mathrm{E}_{\mathrm{g}} / \mathrm{E} \\
\mathrm{s}\end{array}$ & $\begin{array}{c}\text { Elastic modulus } \\
\text { of reinforcement } \\
\text { ring } \mathrm{E}_{\mathrm{g}}(\mathrm{MPa})\end{array}$ \\
\hline \multirow{4}{*}{$1 \sim 16$} & 1 & 100 \\
\cline { 2 - 3 } & 5 & 500 \\
\cline { 2 - 3 } & 10 & 1000 \\
\cline { 2 - 3 } & 20 & 2000 \\
\cline { 2 - 3 } & 40 & 4000 \\
\cline { 2 - 3 } & 80 & 8000 \\
\hline
\end{tabular}

Table 4. Penetration rate table ring of reinforcement ring

\begin{tabular}{|c|c|c|}
\hline $\begin{array}{c}\text { Thickness of } \\
\text { reinforcement } \\
\text { ring }(\mathrm{m})\end{array}$ & $\mathrm{k}=\mathrm{k}_{\mathrm{s}} / \mathrm{kg}_{\mathrm{g}}$ & $\begin{array}{c}\text { Permeability of } \\
\text { reinforcement } \\
\text { ring } \mathrm{k}_{\mathrm{g}}\left(\mathrm{m}^{2}\right)\end{array}$ \\
\hline \multirow{5}{*}{$1 \sim 16$} & 1 & $1 \times 10^{-11}$ \\
\cline { 2 - 3 } & 5 & $2 \times 10^{-12}$ \\
\cline { 2 - 3 } & 10 & $1 \times 10^{-12}$ \\
\cline { 2 - 3 } & 20 & $5 \times 10^{-13}$ \\
\cline { 2 - 3 } & 50 & $2 \times 10^{-13}$ \\
\cline { 2 - 3 } & 100 & $1 \times 10^{-14}$ \\
\hline
\end{tabular}

The numerical simulation results are shown in figure 11 . The vertical settlement of tunnel vault before grouting have serious safety risks. After grouting, the settlement values of the tunnel are greatly reduced. It can be seen from the diagram that under the same thickness of grouting reinforcement ring, the settlement value of tunnel decrease with the increase of elastic modulus of grouting reinforcement ring. But when the elastic modulus of the reinforcement ring increases to a certain extent, the thickness of the reinforcement ring has little effect on the settlement of the tunnel. Under the same elastic modulus of grouting reinforcement ring, the settlement of tunnel decreases with the increase of the thickness of reinforcement ring. But when the thickness of the reinforcing ring is greater than $5 \mathrm{~m}$, the vertical settlement value of the tunnel changes gently.

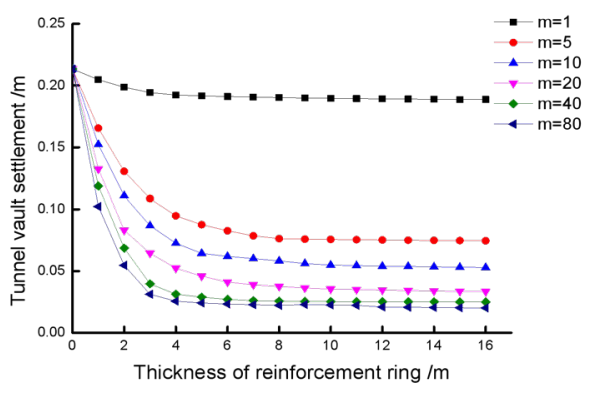

Fig. 11. Change chart of vault settlement.

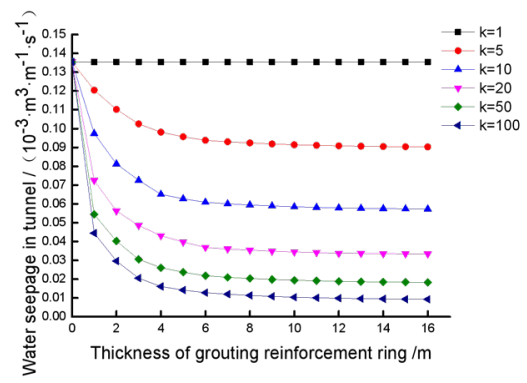

Fig. 12. Change diagram of water leakage.

\subsubsection{The permeability of the tunnel varies with the thickness of the reinforcing ring when the permeability of the reinforcement ring is different}


Thickness of reinforcing ring is set from $1 \mathrm{~m}$ to $16 \mathrm{~m}$, and $\mathrm{n}$ is taken as the ratio of permeability of surrounding rock (ks) to that of grouting reinforcing ring $(\mathrm{kg})$. The permeability of the surrounding rock is $\mathrm{k}_{\mathrm{s}}=1 \times 10^{-11} \mathrm{~m}^{2}$, and $\mathrm{n}$ takes 6 different values, as shown in table 4.

The numerical simulation results are shown in figure 12. Before grouting, the leakage of the tunnel is $1.35 \times 10^{-4} \mathrm{~m}^{3} /(\mathrm{m} / \mathrm{s})$. The permissible seepage is set to $5 \times 10^{-5} \mathrm{~m}^{3} /(\mathrm{m} / \mathrm{s})$. The permeability of the tunnel before grouting is far greater than the allowable value, and there is a serious safety hazard. When the grouting reinforcement ring is formed, the leakage amount of the tunnel will be greatly reduced. It can be seen from the diagram that when the thickness of grouting reinforcement ring is unchanged, the leakage of tunnel decreases obviously with the decrease of the leakage rate of reinforcement ring. When the permeability of reinforcement ring is reduced to a certain extent, the change of seepage volume tends to be gentle. When the permeability of the reinforcing ring is lower than that of the surrounding rock $1 / 50$, the leakage quantity of the tunnel will not change any more. When the grouting reinforcement circle leakage remains unchanged, the tunnel leakage decreases significantly with the increase of reinforcement circle thickness, but when the reinforcement circle thickness is greater than $6 \mathrm{~m}$, the tunnel leakage changes gentle.

\subsubsection{The permeability of the tunnel varies with the thickness of the reinforcing ring when the permeability of the reinforcement ring is different}

The actual project is to reinforce grouting according to the thickness of the selected reinforcement ring $5 \mathrm{~m}$. The numerical simulation software is used to simulate the working condition. The maximum vertical settlement of the tunnel vault is $0.0192 \mathrm{~m}$, and the tunnel leakage is $2.369 \times 10^{-5} \mathrm{~m}^{3} /(\mathrm{m} / \mathrm{s})$ by integrating the tunnel profile with seepage velocity. The maximum settlement value and leakage volume of the tunnel are calculated as safety allowable values. The maximum vertical settlement of the tunnel vault measured in situ is $0.0213 \mathrm{~m}$ and the measured tunnel leakage is $2.293 \mathrm{~m}^{3} /\left(\mathrm{m} /\right.$ day), that is, $2.654 \times 10^{-5} \mathrm{~m}^{3} /(\mathrm{m} / \mathrm{s})$. The measured data show that the effect of grouting reinforcement is remarkable, and the settlement value and leakage amount all reach the control standard range. The results show that the maximum settlement of the simulated tunnel is $9.85 \%$ less than the measured value and the water inflow of the simulated tunnel is $10.73 \%$ less than the measured value. The data obtained from the numerical simulation are basically consistent with the measured data, which verifies the reliability of the numerical simulation.

\section{Conclusion}

(1) Based on the fluid-solid coupling principle of grout in porous media with small pores, a fluid-solid coupling numerical simulation model is established considering the coupling changes of physical and mechanical parameters such as volume strain, porosity, permeability and density of surrounding rock mass in stress field, displacement field and strain field. The vertical settlement of tunnel vault and water leakage caused by tunnel excavation are numerically simulated.

(2) Through the numerical simulation analysis before and after the grouting reinforcement circle formation, the grouting reinforcement circle formation significantly reduces the tunnel vault vertical settlement and tunnel leakage. This is because the elastic modulus, density, cohesion and internal friction angle of grouting stone have been greatly improved compared with water-rich sand layer. At the same time, the grouting reinforcement circle is more compact, and the porosity and permeability decrease significantly compared with the water rich sand layer. 
(3) When the elastic modulus of grouting reinforcement ring is invariable, the vertical settlement of tunnel vault decrease with the increase of grouting reinforcement ring thickness; when the thickness of grouting reinforcement ring is invariable, the vertical displacement decrease with the increase of grouting reinforcement ring elastic modulus. When the permeability of grouting reinforcement ring remains unchanged, the leakage of tunnel decreases with the increase of the thickness of grouting reinforcement ring; when the thickness of grouting reinforcement ring remains unchanged, the leakage decreases with the increase of the permeability of grouting reinforcement ring.

(4) Considering the theoretical feasibility and economic applicability, the optimum thickness of grouting reinforcement ring is $5 \sim 6 \mathrm{~m}$. It is applied to the grouting reinforcement project in stone elderly bathing station of Qingdao Metro. The maximum settlement, displacement and leakage of the tunnel measured on site are in good agreement with the results of numerical simulation, which verifies the reliability of numerical simulation and provides reference for similar projects in the future.

\section{References}

1. Liu R Study on diffusion and plugging mechanism of quick setting cement based slurry in underground dynamic water grouting and its application .2012 China. D. Shandong University.

2. Sui W, Liu J, Hu W, et al Experimental investigation on sealing efficiency of chemical grouting in rock fracture with flowing water 2015 China. J. Tunnelling and Underground Space Technology incorporating Trenchless Technology Research. 50(1):239-49.

3. Zhang Q S, Han W W, Li S C, et al Comprehensive grouting control for water inrush from limestone breccia fracture zone 2012 China. J. Chinese Journal of Rock Mechanics and Engineering.31(12):2412-19.

4. Wang G Study on parameters and stability of curtain grouting reinforcement ring for water rich stratum in tunnel. 2014 China. D. Shandong University.

5. Chen J G, Yuan J Y, Yuan H Q, et al Research and analysis of water inrush and grouting reinforcement ring in Xiang Jia tunnel 2014 China. J. Journal of highway.39(04): :52-56.

6. Li L, Cheng P D, Zhong B C, et al Fluid solid coupling analysis of viscous slurry diffusion in porous medium with small pores 2011 China. J. Research and development of hydrodynamics. 26(02):209-16.

7. Ye X Y and Liu G Y Study on seepage stress coupling characteristics of rock 2005 China. J. Chinese Journal of Rock Mechanics and Engineering. (14):2518-25.

8. Ju M H Numerical simulation of nonlinear dynamic coupling process of mineralization in Dachang ore field, Guangxi 2011 China. D. Central South University.

9. Li S C, Li S C and Xu B S Minimum safety factor method for stability analysis of tunnel surrounding rock 2007 China. J. Rock and Soil Mechanics. 28(03):549-53.

10. Ding $\mathrm{W} T$ and $\mathrm{Xu}$ W J Study on the multiphase fluid-solid interaction in granular materials based on an LBM-DEM coupled method 2018 Switzerland. J. Powder Technology.335(15):301-14.

11. Cui W, Gawecka K A, Potts D M, et al Numerical analysis of coupled thermohydraulic problems in geotechnical engineering $2016 \mathrm{~J}$. Geomechanics for Energy and the Environment.6:22-34. 
12. Tang L S, Sang H T, Song J, et al Mechanical model for failure modes of rock and soil under compression $2016 \mathrm{~J}$. Transactions of Nonferrous Metals Society of China. 26(10):2711-23.

13. Zhao C, Hobbs B E, Muhlhaus H B, et al Numerical modelling of double diffusion driven reactive flow transport in deformable fluid-saturated porous media with particular consideration of temperature-dependent chemical reaction rates $2000 \mathrm{~J}$. Engineering Computations. 17:367-85.

14. He H Z and Wang X H Study on parameters of grouting reinforcement ring for subsea tunnel construction 2008 China. J. Highway traffic technology. (05) :99-102.

15. Monforte L,Arroyo M,Carbonell J M, et al Coupled effective stress analysis of insertion problems in geotechnics with the Particle Finite Element Method 2018 England. J. Computers and Geotechnics.101:114-29 